\section{A water flosser to help maintain optimal oral health}

The Waterpik Water Flosser is a safe and effective adjunct that combines water pressure and pulsations to quickly and easily remove plaque and debris deep between the teeth as well as subgingivally, where string floss and brushes cannot reach.

Since the inception of the first Waterpik Water Flosser, more than 50 years ago over 70 clinical trials have been published, and collectively they demonstrate significant plaque removal, reduction of gingival bleeding and reversal of gingivitis.

For more information on Waterpik, visit www.waterpik.co.uk. Waterpik products are available from Amazon, Asda, Costco UK, Boots.com and Superdrug stores across the UK and Ireland.

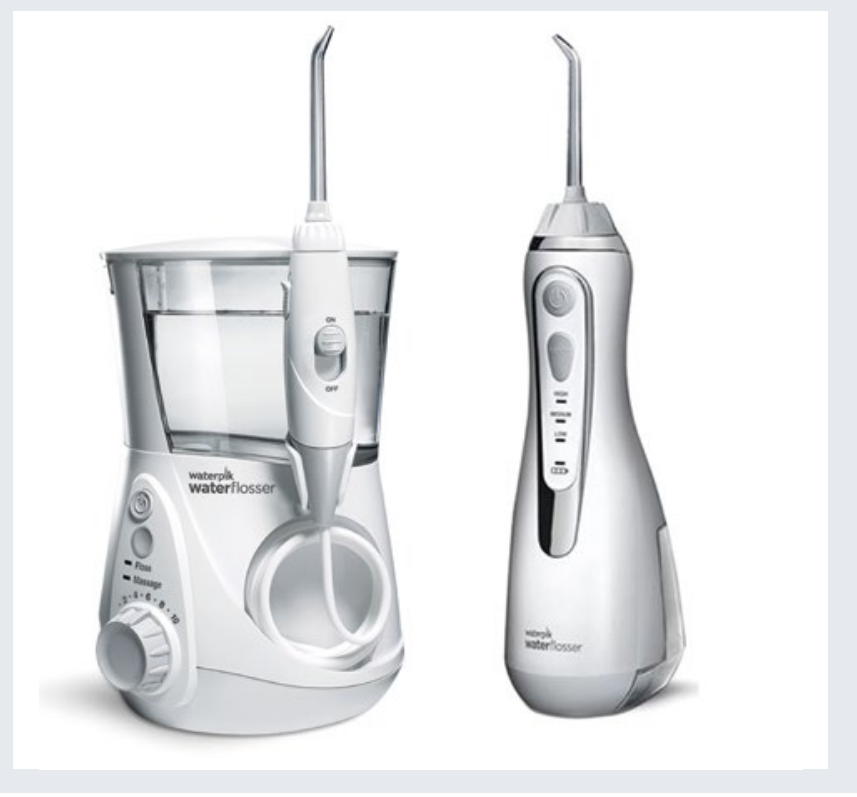

\section{Achieve high patient satisfaction}

Patients suffering from edentulism are likely to have low selfconfidence and may even suffer from malnutrition and other problems as a side effect.

Help improve their standard of living, fast, with the All-on-4 treatment concept from Nobel Biocare.

Utilising just four dental implants, this legendary treatment for edentulism has revolutionised how to treat patients with edentulous jaws, offering a graftless, cost-efficient solution that provides them with a fixed full-arch prosthesis on the day of surgery.

This quickly leads to high patient satisfaction as they can see the improvements in regard to function, aesthetics, speech and self-esteem straight away.

More information can be obtained by contacting Nobel Biocare on 02087563300 or visiting www.nobelbiocare.com/all-on-4.

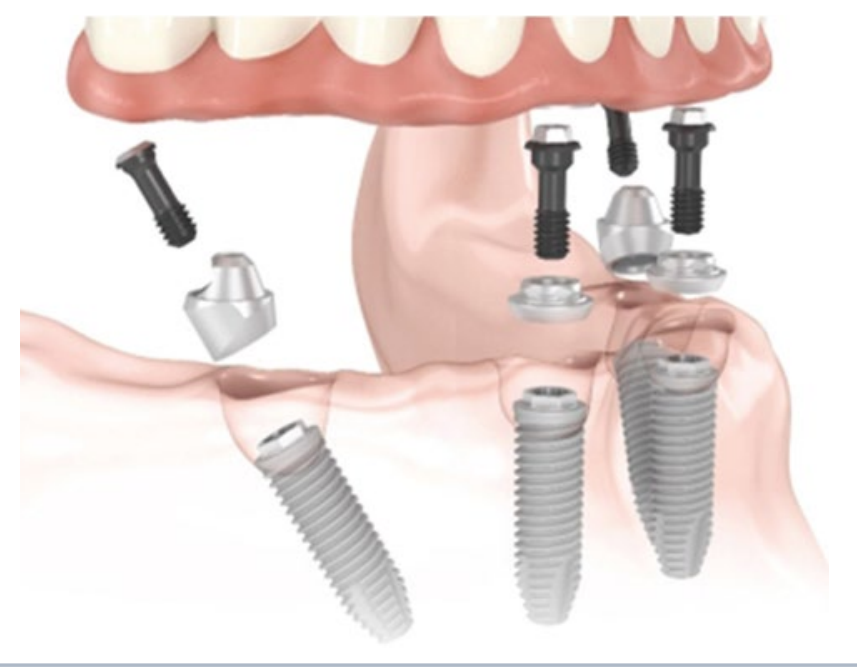

\section{Top marks for company's products}

The prestigious Product Research and Evaluation by Practitioners (PREP) Panel, has roundly recommended Dentsply Sirona’s Class II Solution in a recent practice-based trial.

Dentsply Sirona's Class II Solution System was recently evaluated by the prestigious PREP Panel, led by Professor Trevor Burke.

The independent panel, comprising UK practice-based GDP researchers, has completed more than 70 projects from dental manufacturers - evaluating materials, techniques and conducting clinical evaluations of restorations placed under general dental practice conditions.

The products included in this evaluation were the bonding system Prime\&Bond active, Palodent V3 Sectional Matrix System, SDR Flow+ composite, Ceram.x Universal composite (now known as Ceram.x Spectra ST) and the Enhance Finishing and Polishing System. As a system, the products scored 4.5 out of 5 when appraised across 27 different criteria.

The evaluators praised the individual products which make up the Class II Solution System, saying: 'Excellent product - best bulk fill I have come across' in relation to SDR Flow+, 'Loved the various shades - I have been waiting for this to happen' when considering
Ceram.x and 'Best polishing paste available' with regards to Enhance.

Prime\&Bond active was praised for its 'ease of use', the Enhance Finishing and Polishing System won the recommendation of $83 \%$ of the evaluators, whilst the number of GDPs endorsing the Palodent V3 Sectional Matrix System doubled, from five original users to ten saying they would use in the future.

The PREP Panel was particularly impressed with SDR Flow+ bulk fill and Ceram.x Universal composite, with $92 \%$ saying they would recommend them to colleagues.

Overall, the group was impressed by the performance of individual products but also felt that having all the restorative components in a 'one-stop solution' was a welcome, appealing and cost-effective solution.

Further details on the findings of the PREP Panel are available in a full study report by Professor Trevor Burke, Russell Crisp and Peter Sands available on the Dentsply Sirona website - www. dentsplysirona.com/class2.

More information on the products is available by visiting www. dentsplysirona.com/class2 or calling 01932838338. 